ENSAIO

Recebido em:

10/01/2016

Aceito em: 01/08/2016

\title{
Formação continuada do bibliotecário: a importância da capacitação na área da informática para o profissional da informação
}

\author{
Training continued of the librarian the importance of the \\ qualification in the area of the computing for the professional of the \\ information
}

\author{
Valéria Beatriz ANDRADE \\ Bibliotecária da Medimagem - Universidade Estadual do Piaui - \\ belandrade_180@hotmail.com \\ Antonio Luís FONSECA \\ Bibliotecário do Centro Universitário Uninovafapi - antluys@hotmail.com
}

\section{Resumo}

O ensaio científico visa destacar as vantagens obtidas pelo profissional bibliotecário que opta por uma formação continuada voltada para tecnologia. Explana como tem ocorrido a inserção da informação no mundo tecnológico. Destaca dois pontos: o posicionamento do profissional da informação no mercado de trabalho e a influência positiva que o aperfeiçoamento tecnológico exerce sobre o desempenho deste profissional capacitado a gerenciar a informação interligada aos recursos tecnológicos bem como o auxílio profissional que o bibliotecário, com um amplo conhecimento em informática, tem no manuseio com sistemas automatizados. Optou-se por uma pesquisa bibliográfica, onde foram utilizados livros e artigos publicados sobre o tema.

Palavras-chave: Formação continuada. Tecnologia. Informação. Bibliotecário. Profissional da informação

\begin{abstract}
The scientific test aims to highlight the advantages obtained by the librarian professional who opts for a focused continuing education for technology. Explains as has been the inclusion of information in the technological world. Highlights two points: the positioning of the information professional in the labor market and the positive influence that technological improvement has on the performance of this professional trained to manage the interconnected information technology resources and professional assistance to the librarian, with a broad knowledge in computer science, has in handling with automated systems. It chose a literature search, which were used books and published articles on the topic.
\end{abstract}

Keywords: Continued formation. Technology. Information. Librarian. Professional of the Information.

v. 21, n. 47,2016

p. 124-144

ISSN 1518-2924

$$
\text { . }
$$

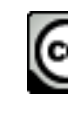

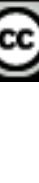

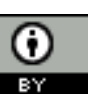

Esta obra está licenciada sob uma Licença Creative Commons. 


\section{INTRODUÇÃo}

Desde o início da utilização das práticas biblioteconômicas para o tratamento com a informação, até os dias atuais, a Biblioteconomia tem sofrido consideráveis mudanças em suas práticas, que vêm sendo alteradas conforme a sociedade vai evoluindo e modificando suas necessidades informacionais. Atualmente, uma forte presença dos meios tecnológicos em bibliotecas e centros de informação tem feito parte do cenário em que o profissional bibliotecário atua.

Nesse contexto surge a necessidade de uma especialização na área tecnológica, por parte desse profissional, que o possibilite a acompanhar essa influência do mundo tecnológico na área da informação, dominando as novas ferramentas utilizadas para esse tratamento com a informação.

0 profissional bibliotecário encontra várias opções para sua atuação no mercado de trabalho, e essa variedade de escolhas amplia-se ao unir as habilidades adquiridas na graduação ao conhecimento tecnológico. Com o acelerado crescimento na produção do conhecimento, os meios eletrônicos se tornaram indispensáveis para o armazenamento e gerenciamento de informações, e nesse contexto, tem se tornado cada vez mais natural a utilização de tais meios, pelo bibliotecário, como seu instrumento de trabalho. A familiarização desse profissional com o mundo tecnológico torna-se ainda mais vantajosa quando o mesmo procura avançar no conhecimento básico de informática, pois isso o possibilitará melhor manuseio dos equipamentos em uma biblioteca. E especializa-se na área, adquirindo conhecimento necessário para, alem de utilizar sistemas de gerenciamentos já prontos, poderem passar a realizar a manutenção desses sistemas, quando necessário, e até mesmo programá-los da maneira que melhor se adéqüem às necessidades e atividades dos centros de informação ou biblioteca que estejam gerenciando.

A formação continuada na área tecnológica para o bibliotecário contribui tanto para esse profissional destacar-se no mercado de trabalho, quanto para que ele tenha domínio sobre ferramentas que o auxiliem na otimização de seu trabalho. Para a confirmação dessa premissa, buscou-se apoio na literatura produzida na área para a realização da presente pesquisa.

0 presente trabalho foi elaborado mediante uma pesquisa que buscou responder ao seguinte questionamento: qual a contribuição oferecida pela capacitação na área de informática para os profissionais da informação? Ao longo do trabalho foram pontuados, então os principais benefícios profissionais agregados ao bibliotecário que opta pela área tecnológica no momento de realizar atividades de formação continuada. Tais pontos buscam alcançar o objetivo geral da pesquisa, que é mostrar a importância que a capacitação na área da informática tem para o profissional bibliotecário.

A questão que originou esse trabalho foi observada em bibliotecas durante visitas feitas para a realização de trabalhos, e durante discussões com colegas de turma do curso de Bacharelado em Biblioteconomia ofertado pela Universidade Estadual do Piauí, que estavam realizando estagio em bibliotecas e arquivos. Nas bibliotecas visitadas, e nos relatos dos colegas foram observadas certas insatisfações por parte dos profissionais gestores das bibliotecas, e por parte dos estagiários, em relação aos sistemas de automação de tais centros, tanto os que eram elaborados por programadores de sistema das próprias instituições onde as bibliotecas ou arquivos estavam inseridos, quanto os programas adquiridos de outros fornecedores.

Tal insatisfação era gerada pelo fato dos sistemas apresentarem alguns detalhes, que modificados, poderiam atender a um maior número de necessidades, ou até mesmo auxiliar de forma mais eficaz o trabalho dos bibliotecários. Porém tais modificações raramente eram possíveis, ou pelo fato do sistema já ter sido adquirido 
pronto e não haver interesse das instituições em custear alterações, ou simplesmente pelos programadores não terem a biblioteca como prioridade no momento de realizarem manutenção e modificações em sistemas.

Observado tal fato, foi gerado o questionamento do por que do próprio bibliotecário não se especializar em áreas da informática que lhe possibilitem a criação de seus próprios sistemas, ou adquirir o conhecimento necessário para fazer a manutenção desses sistemas. Dessa forma acabariam essas divergências entre as características dos sistemas de gerenciamento das bibliotecas, e as reais necessidades sentidas pelos profissionais que as gerenciam.

Assim, o assunto aqui exposto gerou o desejo de realizar um trabalho que explane as vantagens adquiridas pelos profissionais da informação que optam por realizar cursos de formação continuada na área da informática.

O trabalho está disposto em cinco tópicos e quatro subtópicos, iniciando com a apresentação geral do trabalho, feita na introdução, no primeiro capítulo.

Segue-se com o segundo tópico, onde é feito um breve histórico do desenvolvimento da Biblioteconomia ao longo dos anos, e logo após relatando o comportamento da área frente aos recursos que surgiram com os avanços tecnológicos, bem como a adequação das técnicas biblioteconômicas para a utilização de tais recursos em benefício da área. Em seguida é feito uma breve explanação sobre como os recursos eletrônicos têm influenciado na prática da organização da informação.

Após a breve exposição de como o processo de gerenciamento e organização da informação se tem dado frente à tecnologia, o terceiro tópico foi reservado para explicar os aspectos metodológicos utilizados durante a realização da pesquisa que resultou no presente trabalho de conclusão de curso.

Segue-se então com o quarto tópico, onde se explica como vem ocorrendo o processo de formação continuada, de modo geral, pelos profissionais que acabaram de concluir sua graduação em Biblioteconomia, bem como detalhes sobre essa formação quando é voltada para a área tecnológica. Os subtópicos seguintes tratam, respectivamente, do mercado de trabalho que recebe o bibliotecário, e as modificações de suas exigências, ocorridas com o envolvimento da área com a tecnologia; e por fim o subtópico que destaca as consequências benéficas sofridas pelo profissional da informação que decide adquirir habilidades para a manutenção e programação de sistemas automatizados, bem como a especificação das habilidades necessárias para tanto.

No quinto e ultimo tópico estão as considerações finais, feitas a partir do estudo sobre o tema, bem como as conclusões alcançadas após a realização da pesquisa.

\section{EVOLUÇÃO HISTÓRICA DA BIBLIOTECONOMIA}

Segundo Ortega (2002, p.1), a área da Biblioteconomia e documentação pode ser definida "como aquela que abarca o conhecimento teórico e prático da organização e recuperação da informação documentária e sua mediação junto à determinada comunidade usuária". Durante muito tempo a área atuou diante da presença de barreiras físicas, impostas pelos suportes em que a informação, citada nesse conceito, era registrada. Onde a informação produzida restringia-se ao ambiente físico da biblioteca.

A Biblioteconomia era vinculada a uma visão de guardiã da informação. Visão essa adquirida na antiguidade, quando a área, como uma das disciplinas atuantes no campo da informação, se preocupava em registrar todo o conhecimento gerado no mundo, por meio da preservação dos suportes em que esse conhecimento era registrado. Dessa forma chegava a atribuir mais valor ao suporte do que à informação em si. 
Somente no Renascimento surgem as bibliotecas que podem ser consideradas precursoras das bibliotecas modernas. Com o advento da imprensa, no Séc. XVI, a área sofreu o primeiro grande impacto para a informação, quando ocorreu uma explosão na quantidade de publicações pelo mundo. Mas foi no século XVII, com o aparecimento do conceito de biblioteca pública moderna, nos países mais desenvolvidos da Europa e nos Estados Unidos, que fez surgir no mundo a concepção que passou a ser chamada de modernidade, em oposição à imagem que as bibliotecas carregavam de um organismo antigo e medieval, sendo então uma instituição pública, geral e aberta, com acervos gerais de livros e com acesso gratuito ao público. Esse formato permaneceu como ideia de biblioteca moderna até meados do século XX.

Nos últimos séculos, porém, a área da informação tem sido marcada pela era industrial, revolução nas comunicações tecnológicas e, atualmente, pela forte presença das tecnologias da informação. É nesse contexto que a informatização é introduzida na biblioteca. Em 1930 ocorrem as primeiras experiências de automação documentária em bibliotecas nos Estados Unidos, onde o processo de empréstimo era registrado com o uso de equipamentos utilizando-se de cartões perfurados. 0 mesmo procedimento era feito para a realização de pesquisas bibliográficas na França. Apesar de os processamentos técnicos nas bibliotecas já serem realizados de forma automatizada entre as décadas 1950 e 1960, período em que a informatização foi amplamente difundida nas instituições. Foi na década de 1980 que os acervos bibliográficos passaram a ser organizados sistematicamente nas instituições que trabalhavam com esses acervos, graças à difusão dos microcomputadores, mais ágeis e com o valor mais acessível, se comparados aos computadores de grande porte comercializados até os dias atuais.

Neste período o gerenciamento da informação passou a ocorrer de forma mais eficaz, e o bibliotecário passou a integrar-se com o mundo tecnológico. Desde então os avanços tecnológicos na área da informação têm ocorrido com rapidez cada vez maior, influenciando diretamente o trabalho nas bibliotecas e centros de informação em todo o mundo.

Percorrendo pela história das bibliotecas até a atualidade, com o impacto causado pelas tecnologias da informação, três períodos principais são estabelecidos pela literatura da área:

- Biblioteca Tradicional: De Aristóteles (384 a. C) até o início da automação (1960)

- Biblioteca Moderna ou Automatizada: Uso de computadores nos serviços técnicos (catalogação e organização do acervo de 1970 até os dias atuais)

- Biblioteca do Futuro: Considerada a biblioteca eletrônica, sem paredes (recuperação de informações ou texto completo disponível on line) de 1990 em diante

\subsection{Biblioteconomia frente às tecnologias}

Côrte (2002, p. 16) afirma que "se o século XX foi o século da produção industrial, dos bens de consumo durável, o século XXI será o século da informação, da sociedade do conhecimento". Tais evoluções influenciam diretamente nos processos de organização da informação, causando consideráveis alterações no modo de atuação da área de Biblioteconomia. Mudanças essas que causaram um contraditório entre o velho e o novo, ou seja, entre o formato medieval ao qual a área estava vinculada, contra um novo formato introduzido com a presença da tecnologia, agregando à Biblioteconomia uma visão mais moderna e dinâmica.

Para Côrte (2002, p.25):

O cenário indica que se as bibliotecas e arquivos quiserem oferecer melhor serviço aos usuários e cumprir sua missão, necessário se torna acompanhar passo a passo o desenvolvimento da sociedade, entender com melhor precisão os hábitos e os 
costumes dos usuários, adaptarem as tecnologias às necessidades e quantidades de informação de que dispõem, e utilizar um sistema informatizado que privilegie todas as etapas do ciclo documental, onde a escolha recaia sobre uma ferramenta que contemple os recursos hoje disponíveis, sem se tornar obsoleta a médio e longo prazo.

A influência que os avanços tecnológicos têm causado à área da gestão de informação vai além de simplesmente informatizar os centros de informação para o tratamento de seus acervos. Essa influencia está, também, diretamente ligada às necessidades informacionais dos usuários, que devem ser, na realidade, o principal foco desses centros, uma vez que trabalham para servi-los.

No cenário atual, ao qual a autora se refere, os equipamentos tecnológicos estão presentes no cotidiano das pessoas, uma vez que a tecnologia adentrou não somente as instituições que trabalham com a informação, mas também os lares de seus usuários, fazendo parte de suas vidas e auxiliando na realização das mais diversas tarefas.

Essa interação tem aproximado rapidamente os diversos tipos de público à tecnologia e, assim como a realização de diversas atividades cotidianas, a busca pela informação passou também a utilizar-se dos meios tecnológicos, os quais têm se apresentado como eficientes ferramentas nessa busca.

Com o intuito de atender às necessidades informacionais de seus usuários, as instituições que gerem informação têm acompanhado essa modernização integrando tecnologia à suas atividades, alcançando assim maior rapidez e eficácia na recuperação e disseminação da informação a seu público, bem como uma maior integração com esses usuários, já estão integrados com a facilidade e praticidade que o mundo tecnológico oferece. Referente a esses novos modelos organizacionais das instituições, onde as mesmas aproveitam-se dos recursos tecnológicos disponíveis para o auxílio em suas atividades. Assim, Côrte (2002, p. 27) ressalta que:

Essa conjuntura tem levado a um processo de modernização diretamente ligado à automação de rotinas e serviços, com o intuito de implantar uma infra-estrutura de comunicação para agilizar e ampliar o acesso à informação pelo usuário, tornando-se necessária uma ampla visão da tecnologia da informação e sua aplicação nas organizações.

Essa modificação na forma de tratar a informação, proporcionada pela tecnologia, é sentida diretamente pelos profissionais que trabalham com a mesma. São esses profissionais que devem procurar adequar-se aos novos formatos de suportes, que se atualizam em uma velocidade cada vez maior.

Neste contexto, aumenta a importância da necessidade, por parte dos bibliotecários, da compreensão e domínio das técnicas inerentes aos meios informacionais, buscando atingir patamares cada vez mais elevados na utilização da informação em seus diversos âmbitos. Na atualidade, deve atuar como mediador da informação e ensinar a utilização das ferramentas que permitam ao usuário alcançar seus objetivos no que concerne, por exemplo, à recuperação de informações relevantes às suas atividades. (CRESPO; RODRIGUES; MIRANDA, 2006, p.2)

As ferramentas tecnológicas que possibilitam a realização das atividades informacionais estão diretamente ligadas à eficiência na atuação do profissional da informação. Dessa forma, cabe ao profissional bibliotecário, adequar sua função às novidades que surgem constantemente em sua profissão, procurando adaptar-se a um sistema que vem sofrendo modificações rapidamente. 
Para tal adaptação é fundamental uma capacitação na área tecnológica, que lhe possibilite o conhecimento necessário para trabalhar da forma adequada com os recursos os quais a informação tem utilizado como suporte. Dessa forma poderá cumprir sua função de "responder a demandas sociais de informação produzidas pelas transformações tecnológicas que caracterizam o mundo contemporâneo" (VALENTIM, 2002, p.11).

A necessidade de uma especialização na utilização dos meios tecnológicos, por parte dos profissionais da informação, começa a ser sentida no momento em que o computador é introduzido nas bibliotecas e centros de informação ocasionando uma modificação no modo de descrever e recuperar a informação, nos suportes para armazenamento da mesma, e o acesso à sua circulação na Internet. Esse profissional passou a vivenciar, em seu ambiente de trabalho, o aparecimento de recursos eletrônicos servindo de suporte para a produção do conhecimento, como o CD-ROM, as bases de dados eletrônicas, e os catálogos on-line, além de passar a trabalhar diretamente com sistemas de gerenciamento que proporcionaram maior eficiência na recuperação da informação, e a automação dos serviços, antes realizados manualmente, e consequentemente com menor qualidade e rapidez. Apesar dos sistemas de computação terem sidos inicialmente considerados apropriados, particularmente, para instituições com um volume muito grande de transações feitas pelo gerenciamento bibliográfico, atualmente esses sistemas de gerenciamento de bibliotecas são adotados até mesmo por instituições de porte menor, devido à facilidade do acesso aos equipamentos tecnológicos, causada pela expansão da microinformática. Silva $(2005$, p. 16) ressalta que

[...] com o crescimento acelerado dos meios de comunicação e o surgimento das novas tecnologias de informação, o bibliotecário passa a ser um profissional da informação que atua na busca e desenvolvimento de tecnologias que contribuam para a disseminação da informação. Desde então, passou a criar e adaptarem-se aos mais variados mecanismos de conservação e disseminação da informação, dando origem a um ciclo de retroalimentação entre a informação e o suporte de transmissão, aliados à necessidade de muitas outras áreas, num processo tão crescente quanto qualificado.

As modificações ocorridas na forma de tratar a informação ao longo do tempo não devem ser vistas como vilãs pelos profissionais que precisam enquadrarse aos novos moldes, mas sim como facilitadoras para seus processos de trabalho, e como oportunidade de crescimento intelectual, uma vez que, mais conhecimento é agregado a quem busca capacitação tecnológica, além de ampliar as possibilidades de atuação, tornando seu trabalho ainda mais dinâmico e diversificado.

\subsection{A organização contemporânea da informação}

Referindo-se ao trinômio "informação, sociedade e tecnologia", Maranhão (2002, p. 263) o compara com um triângulo equilátero, onde os lados são iguais e cada um dos lados possui o mesmo grau de importância, afirmando que "não há informação sem sociedade, da mesma forma que nenhuma sociedade sobrevive sem informação e nem existe tecnologia sem informação e/ou sociedade". Dessa forma, a organização da informação está sob a influência das condições nas quais a sociedade atual está inserida.

As condições sociais, políticas e econômicas da atualidade são exatamente o que tem causado toda essa evolução no tratamento da informação. Essas técnicas biblioteconômicas às quais o autor se refere têm se desenvolvido em conjunto com a tecnologia, para adequar a organização da informação às atuais necessidades informacionais da sociedade. 
É visível que "[...] a nova sociedade que se estabelece derruba progressivamente as barreiras ao fluxo transfronteira do conhecimento" (AGUIAR, 2000, p.44). A informação, sem filtro e sem restrições, está acessível, em tempo real, sem barreiras e sem a dependência de intermediários, a qualquer um que deseje e que possua as ferramentas necessárias para alcançá-la, tornando ainda mais necessário um bom gerenciamento e um eficiente domínio dos meios nos quais ela se propaga, por parte dos profissionais que com ela trabalham.

Aguiar (2000, p.43) destaca que as transformações as quais o mundo tem sofrido, têm velocidade e proporção que, nem mesmo os mais conhecidos ficcionistas não foram capazes e prever. Referente a influencia tecnológica atuante sobre essas transformações, afirma que as mesmas se devem à

[...] construção de um "ciberespaço" ou de uma "info-sociedade" propiciados, por um lado, por engenhosas associações entre tecnologias diversas, materiais (fibras óticas e semicondutores), miniaturização (chips e microprocessadores), informática (computação, software e hardware, redes), telecomunicação (telefonia, compactação de dados, transmissão por satélites) e serviços - como os tornados possíveis pela Internet e, em especial, pelos sistemas e serviços de informação de caráter factual, documental, pictórico, bibliográfico, estatístico, etc. - e impulsionados, por outro, pelas novas relações econômicas e políticas que se foram construindo.

Pode se afirmar, então que devido à grande variedade de recursos eletrônicos e tecnológicos, e à capacidade de interligar pessoas, que estes possuem, tais recursos se tornaram os principais meios de circulação da informação contida em uma sociedade cada vez mais "dependente" desses recursos. Adquirir conhecimentos tecnológicos para dominar esses recursos significa ter facilidade do acesso a essas informações, que atualmente encontram-se, em sua maioria, registradas em meios eletrônicos, ou seja, para o profissional bibliotecário, que trabalha diretamente com recuperação da informação, tem se tornado indispensável o domínio de tais meios para alcançar seu objetivo: buscar e recuperar a informação certa para o usuário certo.

Barreto (1998, p.122) conceitua fluxo da informação como “[...] uma sucessão de eventos, de um processo de mediação entre a geração da informação por uma fonte emissora e a aceitação da informação pela entidade receptora". Ao explicar esse fluxo, expõe as características de um fluxo tradicional, onde a comunicação era uni direcionada; a estrutura de informação possuía a mesma característica em sua totalidade; existia a mediação entre o receptor e o fluxo da informação; havia um ocultamento de informação; e o julgamento da relevância da informação era feita somente após a interação do receptor com o fluxo de informação. Ao comparar essa forma tradicional, aponta as seguintes características da comunicação eletrônica, e explica a influencia que esta exerce sobre esse fluxo:

- A interação do receptor com a informação: a interação do receptor com a informação é direta, uma vez que esse receptor sai da posição de distanciamento em relação ao fluxo de informação, passando a participar da fluidez desse fluxo sem intermediários;

- Tempo de interação: a interação do receptor com a informação ocorre em tempo real, on-line. A tamanha velocidade de acesso posiciona o receptor em uma nova dimensão para avaliar a relevância e o valor da informação;

- A estrutura da mensagem: o receptor pode utilizar-se de diversas linguagens para elaborar a informação, pois já se desprendeu da estrutura linear da informação;

- A facilidade de ir e vir: uma conexão em rede amplia o espaço de comunicação do receptor, possibilitando que este passeie por diferentes memórias ou estoque de informações no momento desejado. 
O fluxo da informação e o modo como ela circula atualmente são resultados da evolução da comunicação, que tem interferido na emissão da informação e na forma com que ela chega aos receptores que irão adquirir o conhecimento.

\begin{abstract}
A nova realidade afeta, de forma especial, a qualidade, a eficiência e a rapidez do processo de geração do conhecimento científico e tecnológico. Afeta igualmente, de forma brutal, os mecanismos através dos quais o conhecimento resultante do esforço de execução de pesquisas em ciência e tecnologia é comunicado e difundido. É preciso reconhecer, portanto, que não são apenas os cientistas de todas as áreas os que vivem hoje esse mundo novo, mas que, atônito, o profissional da informação também é agente e sujeito desses processos de transformação que tanto impactam seu campo de trabalho. (AGUIAR 2000, p. 38)
\end{abstract}

O perfil e o nível de exigências e necessidades dos usuários tem se modificado ao longo dos anos, devido a esse fácil acesso à informação que os meios modernos têm proporcionado. Esse fato torna indispensável à adequação das habilidades para trabalhar com esses meios por parte dos profissionais da informação, principais responsáveis pelo acesso dos usuários às informações relevantes no momento solicitado.

\title{
3 ASPECTOS METODOLÓGICOS
}

O estudo sobre a formação continuada do profissional bibliotecário foi realizado com base nos artigos publicados em revistas da área de Ciência da Informação, que estudam os detalhes dos processos de formação do profissional bibliotecário. Para o direcionamento do estudo da formação continuada para a área tecnológica buscou-se apoio nos autores da área de Biblioteconomia que estudam os processos de mudança que vem ocorrendo na área a partir da introdução da tecnologia.

Realizou-se então uma pesquisa bibliográfica, que é, segundo Boente e Braga (2004, p.11) "[...] levantamento de informações feito a partir do material coletado em livros, revistas, jornais, artigos, sites da Internet e outras fontes escritas devidamente publicadas", o que auxiliou no conhecimento do histórico da formação continuada e, como seu desenvolvimento deu-se na Biblioteconomia. A pesquisa mostrou também como a introdução da informática e das novas tecnologias na área tem influenciado nas mudanças ocorridas no tratamento da informação e na atuação do profissional bibliotecário nesse novo cenário.

As informações foram captadas tanto de fontes mais atualizadas produzidas na área, bem como artigos e trabalhos apresentados em Congressos e Conferências, por se tratar de um tema em constante atualização e que está presente mais fortemente nesse tipo de fonte. Alguns trabalhos publicados entre as décadas de 80 e 90 também foram consultados para se verificar como os estudos sobre o tema têm evoluído e para compreender melhor a visão dos estudiosos na referida época

A abordagem feita para o estudo foi a qualitativa, devido seu caráter descritivo e a forma de pesquisa realizada foi análise temática. 0 método escolhido foi o descritivo, pois “[...] resume dados de um estudo" Boente e Braga (2004, p.15).

0 caminho percorrido e os métodos apresentados acima foram decididos antes de colocar em prática o referido estudo, levando em consideração a necessidade de decidir o "caminho a ser percorrido" antes de se iniciar uma pesquisa propriamente dita.

\section{EDUCAÇÃo CONTINUADA DO BIBLIOTECÁRIO NA ÁREA TECNOLÓGICA}


A educação continuada tornou-se indispensável aos mais diversos profissionais na sociedade atual, diante da velocidade com que o conhecimento está sendo produzido. É cada vez mais comum a busca pelo complemento ou aperfeiçoamento do conhecimento em determinada área, pelos profissionais, ao concluírem a graduação.

Entre os principais motivos que ocasionam essa busca estão o desejo de adquirir habilidades específicas que possibilitem uma maior probabilidade de sucesso no mercado de trabalho, e a necessidade de aperfeiçoar o conhecimento em áreas em que não foram trabalhadas com tanta especificidade durante a graduação. Para Souza (2007, p. 5)

[...] a formação continuada confere acesso a novos conhecimentos, habilidades e atitudes profissionais sintonizadas com os novos paradigmas da sociedade contemporânea, provocando uma reflexão sobre os processos de trabalhos, que deve ser feita não de forma ingênua, mas com autocrítica.

A busca pelo aprimoramento das habilidades profissionais cresce de acordo com as exigências da sociedade atual, com o intuito de atender às necessidades da mesma, aumentando assim a probabilidade da garantia, por parte desses profissionais, de seu espaço no mercado e da maior eficiência em seu trabalho. 0 profissional que opta pela realização de atividades para sua formação continuada, o faz motivado por um objetivo específico, dessa forma tal opção é feita de forma consciente e direcionada a esses interesses.

Pode-se definir educação continuada "como as atividades educacionais que têm por objetivo atualizar e desenvolver o conhecimento e as habilidades profissionais, de forma a permitir ao profissional um melhor desempenho da sua função" (CRESPO; RODRIGUES; MIRANDA, 2006, p. 3). São atividades que proporcionam ao profissional um conhecimento mais aprofundado que o obtido na graduação, em determinada área, bem como o contato mais direto com um determinado ramo da área de formação. Essas atividades realizam-se em cursos, onde se trabalha com técnicas especializadas; em treinamentos, que trabalham o aperfeiçoamento de atitudes ou desenvolvimentos de potenciais; em participação de eventos, como seminários, congressos e jornadas; ou em cursos de pós graduação, que se dividem em Lato senso (cursos de especialização ou aperfeiçoamentos que abrangem um ramo profissional) e Stricto sensu (mestrados e doutorados). Alem disso, atividades de iniciativa pessoal, como trocas informais de experiência e leituras profissionais e especializadas, também podem ser consideradas como atividades de educação continuada.

Diante da evolução, na forma de tratar a informação, ocorrida ao longo do tempo, é indispensável ao profissional bibliotecário uma constante atualização do conhecimento, que lhe possibilite acompanhar tais modificações. Como afirma Souza (2007, p.6)

A globalização dos meios de comunicação graças às novas tecnologias de informação e comunicação (TIC), em especial internet, trouxe modificações para a vida profissional de várias categorias funcionais, em especial a dos bibliotecários, pois diz respeito diretamente ao conteúdo de seu trabalho: a informação.

Assim como profissionais das mais diversas áreas têm buscado uma continuação em sua formação, os profissionais da informação também se encontram diante dessa necessidade, uma vez que o conhecimento adquirido na graduação nem sempre atende às exigências dos diversos setores de atuação do bibliotecário. Para esses profissionais existem inúmeras opções de cursos e atividades de educação continuada, que podem ser conciliadas às funções bibliotecárias, devido à diversidade de locais onde tais profissionais podem atuar. 
A formação do bibliotecário teve início em 1821, na École Nationale de Chartes, em Paris. Essa escola era voltada para a orientação erudita e teve forte influencia sobre o primeiro curso de biblioteconomia no Brasil, fundado em 1911 no Rio de Janeiro. Em 1887, nos Estados Unidos, surge a School of Library Economy, criada por Melvin Dewey, com a orientação mais técnica. Essa escola influenciou a criação dos cursos paulistas de biblioteconomia no Brasil. A polarização entre a técnica e a erudição sempre marcou a formação do bibliotecário. Somente no século XX, por uma iniciativa da American Library Association (ALA), os norte-americanos souberam harmonizar as duas orientações. Tal iniciativa consistiu em reconhecimento das escolas de biblioteconomia, com o estabelecimento de normas rigorosas, e a promoção de debates e estudos sobre a matéria.

No Brasil a padronização do curso de Biblioteconomia ocorreu na década de $60 \mathrm{com}$ a aprovação do currículo mínimo para o curso, onde foram definidas as disciplinas de História do Livro e das Bibliotecas, História da Literatura, História da Arte, Introdução aos Estudos Históricos e Sociais, Evolução do Pensamento Filosófico e Científico, Organização e Administração de Bibliotecas, Catalogação e Classificação, Bibliografia e Referencia, Documentação e Paleografia, além das disciplinas extracurriculares, que poderiam ser incluídas a critério de cada escola, formando o que era conhecido como currículo pleno. Em 1982 professores da área criaram o currículo mínimo multidisciplinar, através da resolução ${ }^{\circ} 08 / 82$ que foi modificada em 1984, definindo a duração de 4 anos para o curso e alterando a estrutura curricular de forma a equilibrar a concepção norte americana com a francesa. Essa nova proposta definia as matérias instrumentais: Lógica, Língua Portuguesa e Literatura da Língua Portuguesa, Língua Estrangeira Moderna, e Métodos e Técnicas de Pesquisa; as matérias de fundamental geral: Comunicação, Aspectos Sociais, Políticos e Econômicos do Brasil Contemporâneo, e História da Cultura; e matérias de formação profissional: Informação Aplicada à Biblioteconomia, Produção dos Registros do Conhecimento, Formação e Desenvolvimento de Coleções, Controle Bibliográfico dos Registros do Conhecimento, Disseminação da Informação, e Administração de Bibliotecas.

$\mathrm{Na}$ década de 90 houve uma ampliação no campo de atuação do bibliotecário, causada pelo surgimento das novas tecnologias, o que ocasionou a exigências de novos conhecimentos desses profissionais. Diante desse quadro as Diretrizes Curriculares do curso de Biblioteconomia uma maior flexibilidade ao ensino na área. Essas Diretrizes Curriculares foram aprovadas em 2002 incluindo especificações em relação á formação na área de Biblioteconomia, que vai desde as estruturas dos cursos ofertados até as competências dos profissionais formados em tais cursos.

Uma nova classificação foi formada pelos educadores brasileiros e do MERCOSUL, para integrar o núcleo de formação específica na área de Biblioteconomia, com o objetivo de auxiliar no intercâmbio entre professores e alunos e de compatibilizar currículos de escolas de Biblioteconomia. A classificação foi dividida nas seguintes áreas: 1- Fundamentos Teóricos da Biblioteconomia e da Ciência da Informação; 2- Processamento / Organização e Tratamento da Informação; 3- Recursos e Serviços de Informação; 4- Tecnologia da Informação. 5Gestão de Unidades de Informação; 6- Pesquisa. Segundo Davanso e Zanaga (2011, p. 2)

A formação do profissional da informação sob o paradigma da ciência da informação tem como embasamento o ciclo informacional, composto por produção, organização e uso da informação. Seu objetivo é a informação que, ao ser registrada, forma os estoques informacionais utilizados a partir das necessidades do usuário. 
Mesmo tendo adquirido o domínio dos conteúdos na área de Biblioteconomia durante a formação, o profissional bibliotecário necessita de uma constante atualização em sua capacitação, que lhe possibilite acompanhar de forma eficiente a evolução que a área da informação tem vivido. Os cursos de graduação ofertados pelas escolas de Biblioteconomia têm buscado enquadrar-se nessa evolução, mas diante das necessidades de uma sociedade, atualmente, mergulhada no mundo tecnológico, essas adequações não têm sido suficiente, tornando-se fundamental, ao profissional da informação, buscar na formação continuada o conhecimento que o capacite a atender essas necessidades.

No Brasil, os cursos e pós-graduação na área da informação foram criados na década de 70. Apesar do, então, Instituto Brasileiro de Bibliografia e Documentação - IBBT (hoje, Instituto Brasileiro de Informação em Ciência Tecnológica - IBICT) oferecer um curso de pós graduação lato sensu desde 1955, somente em 1970 foram lançados o primeiro Plano Nacional de Pós Graduação - PNPG, com o objetivo de transformar as universidades em centros de atividades permanentes; e o Programa Institucional de Capacitação de Docentes - PICD, objetivando implantar um processo de habilitação para docentes, estimulando o contínuo desenvolvimento de recursos humanos nas instituições de ensino superior, através da formação acadêmica pelos cursos de pós-graduação. A expansão dos cursos de pós-graduação e o processo de auto avaliação dos programas dos cursos de graduação em Biblioteconomia foram ocasionados, nessa época, em virtude desse desenvolvimento ocorrido no ensino superior, em conjunto com a expansão tecnológica, que influenciaram diretamente na formação do profissional bibliotecário. Os cursos de graduação passaram a incluir disciplinas aplicadas pela primeira vez em cursos de pós-graduação, como: bibliografia especializada, mecanização e normalização na documentação.

O número de cursos de pós-graduação na área da informação, e a influência que os mesmos passaram a ter sobre tal área aumentou na segunda metade da década de 70, com o início de alguns cursos de mestrado em biblioteconomia e documentação, impulsionados pelo aumento da necessidade de profissionais qualificados para gerirem bibliotecas universitárias, responsáveis por dar suporte aos próprios cursos de pós-graduação. Inicialmente os cursos de mestrado em biblioteconomia e documentação instalados no país foram o da Universidade Federal de Minas Gerais em 1976, o da Pontifícia Universidade Católica de Campinas em 1977, o da Universidade de Brasília em 1978, e o da Universidade Federal da Paraíba, também em 1978. Atualmente, no Brasil, a área da Ciência da Informação conta com 14 cursos de mestrado e 7 cursos de doutorado. Segundo o site da Associação Nacional de Pesquisa e Pós-Graduação em Ciência da Informação (ANCIB) tais cursos são ofertados atualmente pelas seguintes instituições:

- Instituto Brasileiro de Informação em Ciência e Tecnologia (IBICT): Programa de Pós-Graduação em Ciência da Informação - Mestrado e Doutorado (ambos em convênio com a Universidade Federal do Rio de Janeiro - UFRJ);

- Universidade Federal Fluminense (UFF): Programa de Pós-Graduação em Ciência da Informação - Mestrado;

- Universidade Federal de Minas Gerais (UFMG): Programa de Pós-Graduação em Ciência da Informação - Mestrado e Doutorado;

- Universidade Federal da Paraíba (UFPB): Programa de Pós-Graduação em Ciência da Informação - Mestrado;

- Universidade de Brasília (UNB): Programa de Pós-Graduação em Ciência da Informação - Mestrado e Doutorado;

- Universidade Estadual Paulista: Programa de Pós-Graduação em Ciência da Informação - Mestrado e Doutorado;

- Universidade Federal da Bahia (UFBA): Programa de Pós-Graduação em Ciência da Informação - Mestrado; 
- Universidade Federal de Santa Catarina (UFSC): Programa de Pós-Graduação em Ciência da Informação - Mestrado;

- Universidade Federal de Pernambuco (UFPE): Programa de Pós-Graduação em Ciência da Informação - Mestrado;

- Universidade de São Paulo (USP): Programa de Pós-Graduação em Ciência da Informação - Mestrado e Doutorado;

- Universidade Federal do Rio Grande do Sul (UFRGS): Programa de Pós-Graduação em Comunicação e Informação - Mestrado e Doutorado;

- Universidade Estadual de Londrina (UEL): Mestrado Profissional em Gestão da Informação;

- Universidade Federal do Estado do Rio de Janeiro (UNIRIO): Programa de PósGraduação em Memória Social - Mestrado e Doutorado;

- Universidade Federal do Estado do Rio de Janeiro (UNIRIO): Programa de PósGraduação em Museologia e Patrimônio - Mestrado.

Como oportunidade de aperfeiçoamento profissional através da troca de experiências entre profissionais da área, os bibliotecários têm à sua disposição, no Brasil, alguns eventos, como o Seminário Nacional de Bibliotecas Universitárias SNBU, e Congresso Brasileiro de Biblioteconomia e Documentação - CBBD, entre outros diversos encontros realizados pelo país, onde profissionais da área, alem de compartilhar conhecimentos e experiências, realizam também cursos de aperfeiçoamento em atividades específicas da Biblioteconomia.

Em se tratando de Lato Senso, as opções disponíveis para o profissional da informação são inúmeras, uma vez que, devido à grande quantidade de locais onde os mesmos podem atuar, sua especialização pode ser voltada para as mais diversas atuações, como cursos voltados para organização da informação, comunicação, educação, administração, entre outros. 0 fator determinante na escolha é a especialização profissional exigida pelo ramo de atuação escolhido pelo profissional.

0 atual cenário em que o profissional da informação atua tem exigido do mesmo um elevado nível de conhecimento tecnológico, tornando assim, a formação continuada voltada para a área de tecnologia, uma opção que proporciona consideráveis benefícios. Entre eles, destaca-se a abertura de mais opções no mercado de trabalho, uma vez que um bibliotecário que domina os recursos tecnológicos está um passo a frente do profissional não familiarizado com tais ferramentas. Outro ponto relevante, que pode impulsionar esse profissional à busca pelo conhecimento aprofundado na área tecnológica, é a possibilidade de um maior domínio dos sistemas, que hoje são ferramentas de trabalho (em muitos casos, indispensáveis) do bibliotecário, evitando assim certas divergências que têm ocorrido entre profissionais da informação e profissionais da tecnologia, no trabalho de criação e manutenção de sistemas os quais ambos dependem.

\subsection{Um mercado de trabalho redimensionado}

Referindo-se à postura profissional que o bibliotecário deve assumir na atualidade, Prosdócimo; Ohira (1999, p. 125) afirmam:

O processo de globalização da economia, as inovações tecnológicas, as novas formas de organização do trabalho e os modernos meios de comunicação responsáveis pela criação do espaço virtual, exigem do profissional da informação/bibliotecário, além das capacidades específicas de sua formação, níveis cada vez mais altos de educação, capacidade de trabalho em equipe e de comunicação no ambiente de trabalho, para enfrentar as mudanças existentes. 
Assim como toda a área da informação sofreu alterações ao longo do tempo, o mercado de trabalho que absorve os profissionais da área também alterou suas exigências em relação às características de tais profissionais. Analisando as exigências feitas ao profissional bibliotecário no mercado de trabalho atual, Baptista e Mueller (2005, p. 36) afirmam que

Existe uma demanda por um profissional possuidor de uma visão holística, polivalente ou multiespecializada, pois, para o momento, não basta que esse profissional seja especializado em técnicas de transferência ou organização da informação: é preciso ser um estrategista e entender como funciona um mundo competitivo e globalizado, em constante transformação. Por outro lado, quanto à preparação acadêmica do profissional, verifica-se que as mudanças curriculares são lentas, e a academia é acusada de ter um distanciamento da realidade social.

A garantia de um espaço no mercado de trabalho, bem como sua permanência nele é o principal motivo que leva os profissionais a buscarem a formação continuada após a graduação; e é um motivo relevante a ser levado em consideração pelo profissional bibliotecário no momento de optar por uma dessas atividades, considerando-se que "as exigências do mercado da sociedade da informação atingem especificamente o bibliotecário, pois elas alteram a forma de trabalhar desse profissional" (BAPTISTA; MUELLER 2005, p. 36). Para tais profissionais a opção de realizar sua formação continuada na área tecnológica tornou-se convidativa, levando-se em consideração que, no mercado de trabalho atual, um profissional da informação que domina tecnologia está um passo a frente dos profissionais da mesma área que não estão familiarizados com tais recursos.

Referente ao mercado de trabalho do bibliotecário e a inserção da tecnologia na área da informação, Baptista e Mueller (2005, p. 45) levantaram a seguinte observação:

\begin{abstract}
A literatura da área registrou várias vezes prognóstica para uma provável extinção da profissão, que seria tornada obsoleta pela emergência de tecnologias e mudanças de contexto. A história da profissão, no entanto, mostra uma grande capacidade de adaptação. Com o advento das bases de dados, a profissão incorporou a tecnologia em vez de ser substituída por ela, e o mesmo está acontecendo em relação à Internet.
\end{abstract}

As novas tecnologias trouxeram novas oportunidades no mercado de trabalho para os profissionais da informação. Porém para beneficiar-se de tais oportunidades, é fundamental que esse profissional esteja capacitado para dominar os recursos tecnológicos e garantir uma eficiente atuação nesses espaços que se abriram com a inserção da informação no mundo tecnológico.

A sociedade globalizada do final deste século experimenta inovações tecnológicas que se apresentam com muita rapidez, exigindo dos profissionais da informação a atualização de seus conhecimentos, para melhorar a qualidade e a competitividade dos serviços que prestam a seus usuários. A educação continuada, constante, variada e atualizada se apresenta como o meio adequado e necessário. (PROSDÓCIMO; OHIRA, 1999, p. 125)

A necessidade dessa capacitação tecnológica pelos profissionais da informação é sentida, por exemplo, nos centros que atualmente trabalham com gerenciamento de informação. Os mesmos necessitam frequentemente de suporte técnico por conta do uso indispensável de equipamentos tecnológicos, nos quais estão inseridas as informações. Esse suporte é, geralmente, feito por um profissional especializado em Tecnologia da Informação (T.I.), porém, contar com a presença de 
profissionais da informação capacitados na área de T.I. se torna mais lucrativo e prático para tais instituições, considerando-se que atualmente o que ocorre com mais frequência é a contratação de ambos profissionais, tanto o de T.I., quanto o profissional da informação. Analisando por essa óptica, percebe-se que no momento da contratação, os profissionais bibliotecários que possuem o diferencial da capacitação na área tecnológica, se tornam mais atrativos a tais empresas, uma vez que os mesmos estão capacitados tanto a gerir um centro de informação, como a oferecer o suporte tecnológico aos sistemas automatizados do centro.

Apesar dessa realidade que monta o cenário em que o bibliotecário está inserido, muitos desses profissionais têm mantido distância do aperfeiçoamento tecnológico, optando por especializar-se em áreas mais tradicionais ligadas à Biblioteconomia. Como afirma Crespo; Rodrigues; Miranda (2006, p.6)

[...] toda a informação considerada de interesse pelo profissional é válida, mesmo não estando exclusivamente voltada à área da Ciência da Informação. Deve, isso sim, contemplar a área de interesse ou a lacuna a ser sanada pelo profissional para um melhor desempenho das suas funções.

Com base nesse raciocínio, pode-se afirmar que toda especialização é válida, tendo em vista o conhecimento adquirido. Porém, diante da fusão da área da informação com o mundo tecnológico, que vem ocorrendo com uma velocidade cada vez maior, tais profissionais tendem a isolar-se em uma pequena área do imenso mercado que se prepara para receber os profissionais da informação, optando, em sua maioria, por cursos de formação continuada na área de humanas, voltados para as técnicas mais tradicionais da biblioteconomia, deixando de lado a preocupação em capacitar-se na área tecnológica.

Russo (2010, p.119) afirma que

A economia globalizada, as inovações tecnológicas, os sofisticados meios de comunicação, que levaram à criação do espaço virtual, exigem dos trabalhadores um novo olhar para sua qualificação, que passa por uma boa formação geral e uma grande base tecnológica.

A base tecnológica a qual a autora se refere é, atualmente, essencial para o bibliotecário que anseia acompanhar as alterações pelas quais a sua área de atuação vem passando. Uma base tecnológica necessária ao profissional bibliotecário consiste na aquisição de habilidades que envolvam conhecimento de informática, de formação de redes, de estruturação de bases de dados, na familiarização com implementação de periódicos eletrônicos, bibliotecas virtuais, com os mecanismos de busca para recuperação de dados na Internet, e até mesmo adquirir habilidades de webmaster (auxiliando no desenvolvimento estético e de programação dos sistemas de automação em centros de informação).

Ao concluir a graduação o profissional bibliotecário se vê diante de um vasto leque de opções, que abrange atividades as quais pode realizar e locais onde pode atuar, mas, ao adquirir conhecimentos tecnológicos, esse leque amplia-se consideravelmente e as oportunidades de trabalho aparecem nas mais diversas áreas e instituições. Eis aí um ponto importante a ser levado em consideração no momento de decidir por qual área de formação optar para somar o conhecimento adquirido nesta ao conhecimento adquirido na graduação, mesmo que isso inclua transpor as barreiras encontradas pelos profissionais das áreas de humanas no momento de aprimorar-se em alguns conteúdos da área de exatas, exigidos para o aprofundamento nas habilidades com os recursos tecnológicos. Uma vez quebradas essas barreiras, qualquer profissional, que atue em qualquer área do conhecimento estará apto a adquirir conhecimento necessário para realizar atividades que vão desde alimentar um sistema de automação de biblioteca, com a inserção de um novo 
exemplar, até a programação e construção de um sistema automatizado. Para o profissional que trabalha com informação, quanto maior esse aprofundamento, mais destaque ele terá no mercado de trabalho.

\subsection{Elaboração / manutenção de sistemas de informação}

Mais que contribuir para a ocupação de um bom lugar no mercado de trabalho, o conhecimento tecnológico adquirido pelo profissional bibliotecário é útil, também, para tornar seu trabalho com sistemas de automação mais práticos e eficientes.

Atualmente a automação está presentes nas mais diversas atividades, em praticamente todas as áreas profissionais. Com as tarefas realizadas nas bibliotecas e centros de informação não é diferente, pois cada vez mais estes têm empregado sistemas automatizados para oferecer um atendimento satisfatório a seus usuários.

Nas bibliotecas os sistemas automatizados surgiram nos países mais desenvolvidos, nos anos 60, com o início da utilização dos computadores de grande porte para controlar algumas atividades rotineiras. Esse auxílio que os computadores ofereciam ocorria de forma bastante limitada, visto o baixo nível tecnológico da época. Na década de $80 \mathrm{com}$ maiores avanços tecnológicos, o armazenamento e a recuperação da informação passou a ser feita de forma automatizada, devido a ampliação do uso de computadores. Somente após algumas décadas o uso de sistemas automatizados firmou-se como prioridade, pois inicialmente sua função central era o controle das coleções.

Cardoso (2002, p. 155) pontua os principais motivos que, praticamente, obrigaram as bibliotecas automatizarem seus serviços:

[...] a explosão da informação, percebida, sobretudo através do considerável fluxo de informação em forma eletrônica; a economia de espaço e tempo proporcionada pelo uso dos computadores; e a eficácia nos custos proporcionada pela automação.

Inicialmente algumas instituições apresentaram resistência para aceitar a introdução do computador, pelo temor de desempregos, dos altos custos com a tecnologia, dos treinamentos duradouros, da falta de apoio da gerencia e do trabalho adicional, porém atualmente esses temores foram superados pelo reconhecimento da relevância da automação, restando como principal empecilho a falta de recursos financeiros em algumas bibliotecas.

Com a automatização das bibliotecas e dos centros de informação, o trabalho dos profissionais envolvidos, ou dos que gerenciam tais centros, está diretamente ligado, ou até mesmo, dependente dos sistemas automatizados. Familiarizar-se e dominar o manuseio de tais sistemas tem se tornado essencial para a permanência dos bibliotecários atuando à frente de bibliotecas e dos mais diversos centros de informação e documentação.

Segundo Oliveira e Silveira (2010, p. 4)

[...] o bibliotecário lida cada vez mais com conteúdos informacionais existentes apenas no formato digital, o que, por sua vez, exige capacidade real de trabalhar com sofisticados softwares para processar dados e disponibilizá-los aos usuários, de modos que também fogem ao tradicionalismo das cópias impressas.

É indiscutível a importância de o profissional bibliotecário adquirir a capacidade de trabalhar utilizando softwares sofisticados, porém mais que apenas estar apto a manusear sistemas prontos, o que auxiliaria ainda mais seu trabalho seria a intervenção direta desse profissional na criação de tais softwares, ou até mesmo na programação propriamente dita dos referidos sistemas, aos moldes que 
se adéqüem às necessidades da unidade informacional, detectadas pelos próprios profissionais da informação.

Atualmente um bibliotecário que deseja estar à frente de uma biblioteca ou de um centro de informação deve estar preparado para deparar-se com um sistema automatizado que recupera e armazena informações, e que gerencia toda ou parte da informação que circula em tal centro. Porém, geralmente estes softwares são elaborados por profissionais da área de T.I., que não tiveram uma formação na área de biblioteconomia e documentação e que desenvolvem sistemas para os mais diversos tipos de instituições. Tais profissionais podem ser contratados de uma empresa de fornecimento comercial de sistemas informatizados, que vende um pacote comercial ou a licença de uso do software para o centro de informação, ou podem ser contratados dos próprios centros, onde realizam atividades de T.I, entre elas, elaboração de sistemas. Como esses profissionais não dominam a área da documentação, pois não foram capacitados para gerenciar esses centros, em muitos casos pode ocorrer que os profissionais de T.I não consigam identificar com precisão as reais necessidades dos mesmos, o que reflete em sistemas com algumas falhas por não serem ideais para suprirem tais necessidades.

Quando essas falhas são identificadas pelo profissional da informação, geralmente não podem ser reparadas a tempo hábil, isso porque se o sistema foi adquirido de uma empresa terceirizada, esta cobra um valor considerável para realizar a manutenção de seu sistema e muitas vezes as instituições não estão dispostas a arcar com esse investimento por não valorizarem a importância do bom desempenho dos mesmo para a eficiência do trabalho realizado nas bibliotecas.

Essa dificuldade para a realização de investimentos no setor evidencia-se, principalmente, nas instituições públicas. Mesmo quando as empresas estão dispostas a custear essa manutenção, os devidos reparos e alterações serão realizados mediante um agendamento, respeitando a disponibilidade de tal empresa para a manutenção de seu produto, onde, em muitos casos a empresa não fica localizada na mesma cidade que a instituição que adquiriu o software, o que exigirá um tempo maior para aguardar a realização de tais reparos. A demora na alteração de detalhes dos sistemas também ocorre mesmo nos casos onde os mesmos tenham sido elaborados pelo setor de T.I. da própria instituição, devido à grande quantidade de tarefas pelas quais esse setor é responsável nas empresas, e dificilmente o trabalho da biblioteca é visto como prioridade, estando este sujeito à disponibilidade de tempo desse setor.

Visando um resultado mais satisfatório na elaboração dos sistemas de automação de bibliotecas, esse trabalho é, atualmente, realizado de forma conjunta do profissional bibliotecário com o profissional de T.I.

Normalmente, o gerente da biblioteca não se envolve diretamente com a elaboração do projeto, mas, sim, com a seleção do sistema ou pacote de software que seja mais apropriado. Cada vez mais o gerente de biblioteca e informação mão gerencia o projeto inicial de informatização, mas sim o projeto de melhoramento de um sistema computadorizado já existente. (ROWLEY, 1994, p. 93)

A implementação de um novo sistema ou a substituição de um já existente é realizado mediante um conjunto de tarefas realizadas por ambos profissionais. Para Rowley (1994, p. 93) a necessidade desse trabalho surge em três casos:

- substituição de um sistema manual por um sistema informatizado;

- mudança de um sistema informatizado para outro sistema informatizado;

- modificações, melhoramentos e ampliação de sistemas informatizados já existentes. 
A autora denomina "análise" essa fase onde é feita uma sondagem referente à necessidade da criação ou alteração de um sistema. Identificada essa necessidade dar-se início a um processo, em conjunto, por ambos profissionais, onde os mesmos realizarão um processo que se divide em cinco etapas definidas pela autora. São elas:

- Definição de objetivos: Onde são identificadas as necessidades iniciais, elaboradas as diretrizes e requisitos, iniciada a comunicação de modo que todos os pontos de vistas sejam levados em conta, e são reunidas informações que indicam a forma de atingir os objetivos identificados na "análise". Nessa etapa, pode ser definida a escolha de um sistema específico ou a descrição de um sistema lógico para um sistema já existente;

- Definição dos requisitos do sistema: Essa é a fase onde devem ser definidos detalhes sobre as funções do sistema, bem como seus requisitos específicos, como, por exemplo, as operações que o mesmo abrangerá, as bases de dados que precisam ser criadas, e os usuários do sistema;

- Fase de elaboração do projeto: momento a serem elaborados os modelos lógicos e físicos do sistema. É feita a escolha e a encomenda das configurações de softwares e hardwares, e elaborados os gráficos e fluxogramas das funções e operações que deverão ser executadas pelo sistema.

- Fase de implementação: Momento de fazer o planejamento e a preparação, de realizar a instalação as bases de dados, e do sistema, bem como a identificação das responsabilidades específicas do pessoal. Essa fase normalmente ocorre no período em que o gerente da informação aguarda o cumprimento das datas, após a realização das encomendas. No início será verificado, novamente, como o sistema afetará o então funcionamento da instituição, e os procedimentos a serem realizados devem constar em um cronograma detalhado de cada atividade;

- Fase de avaliação: Com a implementação concluída é necessário concluir o processo avaliando a forma com que o sistema está alcançando o objetivo proposto. É uma avaliação inicial, onde há monitoramento constante e, caso seja necessário, a evolução e manutenção, com o objetivo de melhorar e aperfeiçoar as formas com que o sistema será utilizado.

Mesmo com o trabalho exaustivo realizado ao longo dessas etapas para escolher um sistema que supra as necessidades do centro de informação que o bibliotecário gerencia, geralmente ao final do processo ainda há divergências entre as características apontadas pelo profissional da informação e as presentes no sistema já finalizado, surgindo assim a necessidade de ajustes que irão depender da disponibilidade dos profissionais de T.I. como mencionado anteriormente.

Diante de tais dificuldades, percebe-se que mais que simplesmente conseguir manusear um sistema já pronto, é útil para o bibliotecário ser capaz de programar o próprio sistema com o qual irá trabalhar na instituição. Uma capacitação profissional na área tecnológica, que possibilite o profissional da informação a programar o sistema que será utilizado na instituição irá facilitar essa adequação das reais necessidades da unidade informacional com as características do sistema de gerenciamento.

Velloso (2004, p.159) conceitua programação de sistemas como a "descrição detalhada da relação mais pormenorizada produzida na etapa anterior [análise], escrita de modo que possa ser aceita pelo computador (que irá executá-la)". Essa descrição detalhada de comandos que serão repassadas pelo programador para o computador para que este execute funções, pode ser feita por qualquer pessoa que deseje programar um sistema, mesmo essa pessoa não sendo graduada em Ciências da Computação.

Mesmo sendo, o bibliotecário, um profissional formado dentro da área de Humanas, e a Ciência da Computação esteja inserida na área de Exatas, é possível 
que o mesmo adquira conhecimentos necessários para realizar essa programação, a fim de montar um sistema automatizado. Para tanto, esse profissional, ou qualquer outro que deseje executar a mesma tarefa, sem passar por uma nova graduação, precisa apenas especializar-se para seguir os passos que Farrel $(2010$, p. 6) aponta serem necessários: "entender o problema; planejar a lógica; codificar o programa; usar o software para traduzir o programa para linguagem de máquina; testar o programa e colocar o programa em produção".

Para seguir esses passos e chegar à elaboração de um sistema, é necessário, apenas, que o profissional escolha uma lógica de programação (ou algoritmo), opte por uma linguagem legível por computador, escolha um banco de dados, e aprenda uma programação orientada a objetos. Com esses detalhes definidos é possível programar um sistema com as especificações desejadas pelo programador.

0 trabalho de programação normalmente é realizado pelo o conjunto da atuação de quatro profissionais da área de T.I.: 0 analista, que vai analisar o "ambiente" para adequar o sistema a suas necessidades; o DBA (Data Base Administrador), que trabalha com a montagem do banco de dados; o programador, que realiza a programação propriamente dita do sistema, utilizando as informações coletadas pelo analista e o banco de dados organizado pelo DBA; e o designer, que cuida da aparência do sistema, ou seja, da parte com que o usuário terá contato. Porém, em muitas instituições, apenas um profissional exerce essas quatro tarefas, podendo assim programar um sistema (em especial os sistemas mais simples) utilizando essas habilidades específicas. 0 conhecimento necessário para trabalhar com essas ferramentas pode ser adquirido tanto em cursos técnicos ou tecnólogos da área da Computação, ou simplesmente com um estudo da literatura da área, que oferece conteúdo suficiente para, aliado com a prática, capacitar um profissional de qualquer outra área a programar um sistema informatizado. Cabe ao profissional bibliotecário a decisão em optar por esse esforço como um investimento profissional para um desempenho mais eficaz de sua profissão.

\section{CONSIDERAÇÕES FINAIS}

É natural que no momento de optar por fazer um curso superior as pessoas façam a escolha por um curso na área a qual se identificam. Dificilmente alguém que tenha afinidade com a área da Saúde, por exemplo, opte por fazer a graduação em um curso inserido na área de Humanas, e, consequentemente a mesma preferência prevalece no momento da escolha por uma pós graduação.

Esse posicionamento não é diferente na área da informação. Por estar, o curso de Biblioteconomia, inserido na área de Humanas, este atrai pessoas com afinidade por essa área, e depois de concluída a graduação os profissionais nem sempre desenvolvem interesse por especializarem-se na área da computação, por exigir certa familiarização com as Ciências Exatas, e em muitos casos, alguns profissionais não têm a preocupação, até mesmo, em dominar recursos tecnológicos, cada vez mais presentes nas instituições que trabalham com gerenciamento de informação.

A literatura na área da informação e documentação aponta com cada vez mais enfoque o desenvolvimento da mesma em paralelo com a tecnologia. Portanto, a especialização na área da computação, ou simplesmente um maior esforço em familiarizar-se com a tecnologia é uma questão de consciência para o bibliotecário que deseja manter-se no mercado de trabalho, pois seu principal instrumento de trabalho, a informação, é atualmente, um elo que liga Biblioteconomia e tecnologia. 0 profissional que não estiver inserido nesse processo, conforme a evolução pela qual a área vem passando, será inevitavelmente excluído aos poucos do mercado e trabalho. 
Garantir uma vaga no mercado de trabalho não será suficiente se o profissional não estiver em uma constante busca pelo aperfeiçoamento de suas habilidades. Conforme o profissional da informação vai interagindo com a tecnologia, seu conhecimento vai ampliando-se e facilitando seu trabalho com os novos recursos que forem surgindo, o torna o gerenciamento da informação mais eficaz, gerando melhores resultados para quem a busca. Eis a importância, para o desempenho profissional, de se estar em constante aprendizado, em especial quando se trata das próprias ferramentas de trabalho.

Nada mais atrativo para o mercado de trabalho que um profissional que, com seu conhecimento, otimiza seu trabalho tornando-o mais eficiente. A participação direta do profissional da informação na elaboração ou manutenção do sistema automatizado utilizado na instituição onde o bibliotecário atua, contribui para uma maior eficiência no gerenciamento da informação, uma vez que este profissional poderá aliar o conhecimento voltado para a informação e documentação, adquirido na graduação, com um conhecimento em computação adquirido em uma formação continuada na área, que o possibilite a criar sistemas sem a interferência de um profissional da área de T.I. que, em muitos casos não adéqua as funções do sistema às reais necessidades dos centros de informação, como resultado de uma divergência do modo de pensar e trabalhar de ambos profissionais.

Uma formação continuada que possibilite o bibliotecário a atingir esse nível de atuar na programação de sistemas exige esforço e tempo aplicado nesses estudos, porém deve ser visto como um investimento profissional que terá como consequências um destaque no mercado de trabalho e um bom retorno financeiro, uma vez que ainda são poucos os profissionais da informação que trabalham com desenvolvimento de softwares voltados para bibliotecas e centros de informação, principalmente em áreas específicas do país.

0 interesse pela especialização na área tecnológica já é presente em muitos profissionais, tanto pela percepção de como a Biblioteconomia está inserida no mundo tecnológico, como pela grade curricular adotada por algumas universidades que ofertam o curso, onde já estão presentes muitas disciplinas voltadas para tecnologia. Porém muitos profissionais, principalmente os graduados nas regiões norte e Nordeste do Brasil, onde a graduação não é tão voltada para a área tecnológica como em outras regiões do país, ainda precisam reformular sua visão referente às atividades biblioteconômicas, e perceber que a evolução tecnológica da Biblioteconomia não é algo que ainda vai ocorrer, mas algo que já ocorreu e que no presente momento está apenas se tornando mais consistente.

\section{REFERÊCIAS}

AGUIAR, Afrânio Carvalho. Derrubando-se as barreiras ao fluxo transfronteira do conhecimento. In: LUBISCO, Nídia M. L.; BRANDÃO, Lídia M. B. (Orgs.) Informação e informática. Salvador: EDUSBA, 2000, p. 37-63.

BAPTISTA, Sofia Galvão; MUELLER, Suzana Pinheiro Machado. Considerações sobre o mercado de trabalho do bibliotecário. Información, Cultura y Sociedad, Buenos Aires, n. 12, p.35 - 50, 2005. Disponível em: http://repositorio.unb.br/bitstream/10482/976/2/ARTIGO ConsideracoesMercadoTrabalh oBibliotecario.pdf. Acesso em: 02 nov. 2014.

BARRETO, Aldo de Albuquerque. Mudança estrutural no fluxo do conhecimento: a comunicação eletrônica. Ciência da Informação, Brasília, v. 27, n. 2, p. 122 - 127, maio/ago. 1998. Disponível em: http://www.scielo.br/pdf/ci/v27n2/barreto.pdf. Acesso em: 01 nov. 2014. 
BOENTE, Alfredo; BRAGA, Gláucia. Metodologia científica contemporânea. Rio de Janeiro: Brasport, 2004.

CARDOSO, Liana Rosa Brito. Automação de bibliotecas: tendências contemporâneas. In: TARGINO, Maria das Graças; CASTRO, Mônica M. M. R. N. de (Orgs.). Desafiando os domínios da informação. Teresina: UFPI, 2002. p. 153 - 181.

CÔRTE, Adelaide Ramos et al. Avaliação de softwares para bibliotecas e arquivos: uma visão do cenário nacional, 2. ed. São Paulo: Polis, 2002.

CRESPO, Isabel Merlo; RODRIGUES, Ana Vera Finardi; MIRANDA, Celina Leite. Educação Continuada para bibliotecários: características e perspectivas em um cenário de mudanças. Revista Biblios, Porto Alegre, n. 25 - 26, 2006. Disponível em: http://eprints.rclis.org/8801/1/25 08.pdf. Acesso em: 20 mar. 2014.

DAVANSO, Andressa Mello; ZANAGA, Mariângela Pisoni. Organização curricular dos cursos de Biblioteconomia brasileiros. In: ENCONTRO DE INICIAÇÃ̃O CIENTÍFICA, 16 e ENCONTRO DE INICIAÇÃO EM DESENVOLVIMENTO TECNOLÓGICO E INOVAÇÃO DA PUC-CAMPINAS, 1., 2011, Campinas. Anais eletrônicos... Campinas, 2011. Disponível em:

http://www.academia.edu/1017248/

Organiza\%C3\%A7\%C3\%A3o curricular dos cursos de Biblioteconomia brasileiros Acesso em: 01 nov. 2014.

FARREL, Joyce. Lógica e design de programação: introdução. São Paulo: Cengage Learning, 2010.

MARANHÃO, Tarcila Barros Nunes. Informação, sociedade e tecnologia. In: TARGINO, Maria das Graças; CASTRO, Mônica M. M. R. N. de (Orgs.). Desafiando os domínios da informação. Teresina: UFPI, 2002. p. 263 - 277.

OLIVEIRA, Lais Pereira de. SILVEIRA, Carlos Eduardo da. Desafios do bibliotecário frente às novas tecnologias da informação e comunicação. In: ENCONTRO REGIONAL DE ESTUDANTES DE BIBLIOTECONOMIA, DOCUMENTAÇÃO, GESTÃO E CIENCIA DA INFORMAÇÃO, 12., 2010, Porto Alegre. Anais eletrônicos... Porto Alegre, 2010. Disponível em: $\underline{\text { http://pt.scribd.com/doc/ }}$

48656094/Desafios-do-bibliotecario-frente-as-novas-tecnologias-da-informacao-ecomunicacao. Acesso em: 03 nov. 2014.

ORTEGA, Cristina Dotta. Introdução ao MicroISIS. 2. ed. Brasília: Briquet de Lemos/Livros, 2002.

PROSDÓCIMO, Zulma Pures Alves; OHIRA, Maria de Lourdes Blatt. Educação continuada do bibliotecário: revisão de literatura. Revista ACB. Florianópolis, v. 4, n. 4, p. 111 - 128. 1999. Disponível em: http://www.brapci.inf.br/article.phpdd $0=000000$

8165. Acesso em: 04 nov. 2014.

ROWLEY, Jennifer. Informática para bibliotecas.Brasília: Briquet de Lemos/Livros, 1994.

RUSSO, Mariza. Fundamentos de biblioteconomia e ciência da informação. Rio de Janeiro: e-papers, 2010.

SILVA, Fabiano Couto Corrêa da. Bibliotecários especialistas: guia de especialidades e recursos informacionais. Brasília: Thesaurus, 2005.

SOUZA, Elisabete Gonçalves de. A formação continuada do bibliotecário face às exigências das novas tecnologias.2007. Disponível em: http://alb.com.br/arquivomorto/edicoes anteriores/anais16/sem02pdf/sm02ss04 01.pdf. Acesso em: 02 nov. 2014. 
VALENTIM, Marta Lígia Pomim. Prefácio. In: CÔRTE, Adelaide Ramos et al. Avaliação de softwares para bibliotecas e arquivos: uma visão do cenário nacional, 2. ed. São Paulo: Polis, 2002.

VELLOSO, Fernando de Castro. Informática: conceitos básicos. Rio de Janeiro: Elsevier, 2004.

Editores do artigo: Adilson Luiz Pinto, Rafaela Paula Schmitz e Enrique Muriel-Torrado 